\title{
Araştırma Geliştirme Harcamaları ve Ekonomik Büyüme İlişkisi Üzerine Bir Panel Veri Analizi*
}

\author{
Durmuş Çağrı Yıldırım, ${ }^{\text {a,*** }}$ Tuğba Kantarcı ${ }^{\mathrm{b}}$ \\ ${ }^{a}$ Doç. Dr., Namık Kemal Üniversitesi, İktisadi ve İdari Bilimler Fakültesi, İktisat Bölümü, 59030, Tekirdağ/Türkiye. \\ ORCID: 0000-0003-4168-2792

 \\ ORCID: 0000-0002-2257-430X
}

A Panel Data Analysis on the Relationship between Research \& Development Expenditure and Economic Growth

\section{MAKALE BILGISİ}

\section{Makale Geçmişi:}

Başvuru tarihi: 19 Ocak 2018

Düzeltme tarihi: 12 Mart 2018

Kabul tarihi: 25 Mart 2018

\section{Anahtar Kelimeler:}

Ar-Ge

Yenilik

Ekonomik Büyüme

Panel Veri Analizi

\section{ARTICLE INFO}

\section{Article history:}

Received 19 January 2018

Received in revised form 12 March 2018

Accepted 25 March 2018

\section{Keywords:}

R\&D

Innovation

Economic Growth

Panel Data Analysis
ÖZ

Yenilik, küreselleşen rekabet ortamında fark ve değer yaratabilmenin en önemli yoludur. Bu nedenle yenilik, ekonomide katma değer yaratarak büyümenin itici gücü olan bir etken olarak gösterilmektedir. Ar-Ge ise söz konusu yeniliklerin ortaya çıkmasında önemli rol oynayan sistemli çalışmalar bütünü olarak ifade edilmektedir. Bu çalışmanın amacı gelişmekte olan ülkelerde ArGe'nin ekonomik büyüme üzerine etkilerinin araştırılmasıdır. Çalışmada, 1998-2013 dönemi yıllık verileri kullanılarak Ar-Ge harcamalarının ekonomik büyüme üzerindeki etkisi 15 gelişmekte olan ülke için panel veri analizi ile incelenmiştir. Elde edilen sonuçlara göre Ar-Ge harcamalarının ekonomik büyüme üzerinde istatistiksel olarak anlamlı bir etkiye sahip olmadığı görülmüştür.

\section{A B S T R A C T}

Innovation is the most important way to make a difference and values in a globalizing competitive environment. For this reason, innovation is shown as the driving force for growth by creating added value in the economy. $R \& D$ is expressed as systematic studies that play an important role in the emergence of innovations. The aim of this study is to investigate the effects of R\&D and innovation on the economic growth in the developing countries. In this study, the impact of R\&D expenditure on economic growth using annual data for 1998- 2013 period was analyzed by panel data analysis for 15 developing countries. According to the results, it was seen R\&D expenditures did not have a statistically significant effect on economic growth.
\end{abstract}

\section{Giriş}

Sanayi Devriminden bu yana bilim ve teknolojideki gelişmeler ülkelerin ekonomik ve sosyal alanda birçok değişime uğramasına neden olmuştur. Teknolojik gelişmeler, insan hayatını kolaylaştırma, reel gelir artışı sağlama, verimlilik, bireylerin yaşam standartlarının artırılması gibi konularla birlikte büyüme ve gelişme üzerinde doğrudan etkiye sahip olduğu söylenebilir. Teknolojik gelişmeler, araştırma ve bilimsel bilgi birikimine

\footnotetext{
* Bu çalışma, 2017 yılında Namık Kemal Üniversitesi Sosyal Bilimler Enstitüsü tarafindan kabul edilen “Ar-Ge ve Yeniliğin Gelişmekte Olan Ülkeler Bağlamında Makroekonomik Performans Üzerine Etkisi" adlı Yüksek Lisans tezinden türetilmiş ve 20-21 Mayıs 2017 tarihlerinde İstanbul'da düzenlenen International Congress of Management Economy and Policy isimli kongrede bildiri olarak sunulmuştur.

** Sorumlu yazar/Corresponding author.

e-posta: dcyildirim@nku.edu.tr
} 
bağlı olarak yürütülen çalışmalar sonucunda ortaya çıkan icatlar ve yenilikler olarak kendini göstermektedir.

Üretim faktörlerinden biri olarak gösterilen teknolojik gelişmeler, ekonomide üretimi artırıcı ve maliyetleri düşürücü özelliğe sahiptir. Yeni ekonomi içerisinde yer alan, teknik bilgi (teknoloji) temel üretim faktörü olarak ifade edilmektedir (Öztürk, 2013: 211). Teknolojik gelişmelerle birlikte ortaya çıkan yenilik; yeni fikirlerin anlamlı çıktılara dönüştürülme sürecidir. Yenilikler, değer yaratacak ürün ya da hizmetlerin yeni yol ve yöntemlerle ortaya çıkması için yürütülen çalışmalarla elde edilmektedir. Yeniliğin ortaya çıkmasında Ar-Ge faaliyetleri önemli rol oynamaktadır.

Yenilik, dar anlamıyla sadece refahın yükseltilmesi ve refahı artırma çabasının bir yolu olmaktan farklı olarak insanların daha önce yapılmamış şeyleri yapmalarına firsat sağlaması açısından önem taşıyan bir kavramdır. Bu bakımdan yenilik, yeniliği sadece kendi ülkelerinde sürdürmek ve artırmak isteyenler için değil, ekonomik gelişmenin yönünü değiştirmek ve yaşam standardını iyileştirmek isteyenler için büyük önem arz etmektedir (Freeman ve Soete, 2004: 2).

Yeniliği tarihsel açıdan ilk ele alan iktisatçılar arasında Adam Smith'in “Milletlerin Zenginliğii”, David Ricardo'nun "Siyasal İktisadın ve Vergilendirmenin İlkeleri" ve Karl Marx'ın "Kapital" adlı eserleri dikkat çeker. Bu iktisatçılar eserlerinde yenilik kavramına değinmişler fakat yeniliğin büyümenin itici bir gücü olacağına dair varsayımda bulunmamışlardır. Sonrasında Marx'ın fikirlerinden büyük ölçüde etkilenen Joseph Schumpeter ise, yenilikle ilgili yoğun çalışmalar yapan ve birçok büyüme modelinde görüşlerinden yararlanılan iktisatçı olarak bilinmektedir. 1942 yılında çıkardığı "Capitalism, Socialism and Democracy" isimli kitabında "yaratıcı yıkım" teorisinden bahsederek yenilik ile ilgili görüşlerini belirtmiştir.

Kapitalist sistemi çalıştıran ve sürekliliğini sağlayan, yeni tüketim maddeleri, yeni üretim yöntemleri, yeni ulaşım yolları ve pazarlar, yeni endüstriyel örgütlenmelerin türleri sonucunda ortaya çıkmıştır. Bütün hepsi kapitalist mekanizma tarafından yaratılmıştır. Tarım üretiminde kullanılan alet ve ekipmanlar yerini çağdaş tarımda kullanılan makinelere, enerji sektöründe kullanılan su değirmenleri yerini modern tribünlere, ulaştırmada ise kullanılan posta arabaları yerini uçaklara bırakarak belli periyotlarla sürekli bir değişim yaşanmıştır. Yeni milli pazarların veya dış pazarların açılması, el sanatları atölyelerinden büyük işletmelere geçiş gibi değişimler kapitalist sistemin sürekli olarak iç dinamiklerden kaynaklanan bir devrim ve yenilenme havası içinde olmasını sağlamıştır. Bütün bunlar devamlı olarak eskileri yok ederek, yenilerini yaratmaktadır. Bu süreç “yaratıcı yıkım” olarak adlandırılırken, kapitalist sistemin gelişimi için her girişimcinin bu gelişime er veya geç ayak uydurmanın zorunlu olduğuna dikkat çekilmiştir (Schumpeter, 2014: 103).

Ar-Ge ise, bilgi birikiminin ve deneyimin gelişmesi için sistemli bir şekilde yapılan çalışmalar olarak adlandırılmaktadır. Ar-Ge, "yeni ürün veya yeni üretim süreçlerinin geliştirilmesi" ni içerir (MÜSİAD, 2012). Ar-Ge çalışmaları üç faaliyeti kapsamaktadır. Bunlar temel araştırma, uygulamalı araştırma ve deneysel geliştirmeden oluşmaktadır (OECD, 2002). Temel araştırma, ticari bir amaç gütmeyen, bilimsel bilginin geliştirilmesini hedefleyen özgün çalışmalar olarak açıklanmaktadır. Temel araştırma, yeni hipotezler, kuramlar ve genel yasalar meydana çıkararak, olayların ve varlıkların değerini ve anlamını bulmaya çalışır (Barutçugil, 2009: 28). Uygulamalı araştırma, yeni bilgi elde etme amacıyla üstlenilen özgün bir araştırma olmasıyla birlikte, öncelikle belirli bir pratik amaç ya da hedefe yöneliktir (OECD, 2002). Deneysel geliştirme, genellikle temel araştırma ve uygulamalı araştırma bulgularından hareketle, yeni ürünlerin, sistemlerin, üretim süreçlerinin meydana çıkarılmasını ve var olanların ise geliştirilmesine yönelik kullanılmasını ifade etmektedir (Barutçugil, 2009: 29).

Büyüme kavramı ülkelerin yakından ilgilendiği bir olgu olup, kişi başına reel hasılada meydana gelen sürekli artış olarak açıklanmaktadır. Bu nedenle büyümenin açıklanması için birçok model geliştirilmiş ve bu modellerle ekonomik büyümenin kaynaklarına dikkat çekilmiştir. Büyüme teorileri 1950'lerde ortaya çıkan "Dışsal Büyüme Teorileri" ve 1980'lerde ortaya çıkan "Yeni İçsel Büyüme Teorileri”" olmak üzere iki grupta toplanmıştır. Dışsal büyüme teorileri, daha çok işgücü, azalan verimler yasası, sermaye gibi konular üzerinde yoğunlaşmış teknolojik yeniliği dışsal olarak ele almıştır. $\mathrm{Bu}$ büyüme modellerinin bazı varsayımlarını sorgulayan iktisatçılar yeni içsel büyüme modellerini geliştirmiştir. İçsel büyüme teorilerinin geliştirilmesinde dikkat çeken iktisatçılar arasında Romer, Lucas, Barro, Grosmann ve Helpman, Aghion ve Howit gelmekte, yeniliği içsel kabul edip, Ar-Ge ve yeniliği büyümenin kaynaklarından biri göstermişlerdir.

Literatürde yenilik ve Ar-Ge'nin ekonomik büyüme üzerindeki etkisi geniş bir şekilde incelenmiştir. Çalışmalarda Ar-Ge, yenilik ve büyüme arasındaki ilişki zaman serisi analizi ve panel veri analizi yöntemleri kullanılarak tahmin edilmeye çalışılmıştır. Falk (2007), 1970-2004 yıllarını kapsayan dönemde OECD ülkeleri için Ar-Ge harcamalarının uzun vadeli ekonomik büyüme üzerinde etkisini incelemiştir. Yöntem olarak panel veri analizi dinamik bir büyüme modeli ile tahmin yapılmıştır. Elde edilen bulgulara göre Ar-Ge harcamalarının ve yüksek teknoloji sektöründeki Ar-Ge yatırımlarının payının kişi başı GSYH ve çalışılan saat başı GSYH üzerinde güçlü ve pozitif bir etkiye sahip olduğu tespit edilmiştir. Altın ve Kaya (2009), 1990-2005 yılları, Türkiye için Ar-Ge harcamaları ve ekonomik büyüme arasındaki ilişkiyi incelemişlerdir. Serilerin durağanlığını belirlemek için ADF birim kök sinamas1, FPE (Final Prediction Error) ve AIC (Akaike Information Criterion) kriterlerine göre gecikme uzunluğu, eş-bütünleşme testi, VEC modeli ve Granger nedensellik yöntemleri kullanılmıştır. Sonuç, Ar-Ge harcamalarından ekonomik büyümeye doğru uzun dönemli bir nedensellik ilişkisi olduğunu göstermektedir. Samimi ve Alerasoul (2009), 2000-2006 yılları 30 gelişmekte olan ülke için Ar-Ge harcamaları ve ekonomik büyüme arasındaki ilişkiyi panel veri regresyon modeli kullanarak incelemişlerdir. Elde edilen bulgulara göre Ar-Ge harcamaları ve ekonomik büyüme arasındaki ilişkinin negatif ve anlamsız olduğu tespit edilmiştir. Korkmaz (2010), 1990-2008 yıllarını kapsayan dönemde Türkiye için Ar-Ge harcamaları ve ekonomik büyüme arasındaki ilişkiyi incelemiştir. Serilerin durağanlığını belirlemek için ADF ve Philips-Perron birim kök sınaması yapılmıştır. Akaike, Schwarz ve Hannan-Quin bilgi kriterleri kullanılarak gecikme sayısı belirlenmiş, Johansen eş-bütünleşme ve Granger nedensellik analizi ile 
test edilmiştir. Granger nedensellik testi sonucunda kısa dönemde Ar-Ge harcamalarının GSYH'yi etkilediği tespit edilmiştir. Yaylalı, vd. (2010), 1990-2009 yılları Türkiye için Ar-Ge harcamaları ve ekonomik büyüme arasındaki ilişkiyi ADF, eş-bütünleşme ve Granger nedensellik analizi uygulayarak test etmişlerdir. Ar-Ge harcamaları ve ekonomik büyüme arasında tek yönlü bir ilişki saptanmıştır. $\mathrm{Bu}$ ilişkinin yönü $\mathrm{Ar}-\mathrm{Ge}$ harcamalarından ekonomik büyümeye doğru olduğu tespit edilmiștir. Petrariu, vd. (2013), ekonomik büyüme ve yenilik arasındaki ilişkiyi 1996-2010 dönemi Orta ve Doğu Avrupa ülkeleri için panel model kullanarak incelemişlerdir. Bulgular, mevcut rekabet ile yeniliğin ekonomik büyüme ve ulusal rekabetçiliğe önemli katkı sağladığını göstermekte ve Batı ve Doğu ekonomileri arasındaki farkın yeniliğe yatırım yapılarak azaltılabileceğine işaret etmektedir. Wang vd. (2013), 19912006 yıllarını kapsayan dönemde 23 OECD ülkesi ve Tayvan için yüksek teknoloji sektöründeki Ar-Ge harcamalarının ekonomik büyüme üzerindeki etkisini incelenmişlerdir. Yöntem olarak quantile regresyon tekniği kullanılmıştır. Elde edilen bulgulara göre yüksek teknoloji ürünü Ar-Ge harcamalarının, kişi başına düşen GSYH üzerinde pozitif ve güçlü bir etkisi olduğunu göstermektedir. Silaghi vd. (2014), 1998-2008 y1lları Orta ve Doğu Avrupa ülkeleri için özel ve kamu Ar-Ge harcamalarının büyüme hızı üzerindeki etkisini dinamik bir panel veri tekniği Arellano-Bond'un Genelleştirilmiş Momentler Metodu'nu (GMM) kullanılarak incelemişlerdir. Elde edilen bulgulara göre, işletmelerin Ar-Ge yoğunluğundaki \% 1'lik artış, kısa dönemde ilgili ülkelerde büyümeyi 0.050 , uzun dönemde ise \% 0.213 artırdığ 1 tespit edilmiştir. Kamu Ar-Ge harcaması istatiksel olarak anlamsız bulunmuştur. Ayrıca modele beşeri sermaye değişkeni ilave edildiğinde Ar-Ge harcamasının büyüme üzerindeki etkisi azalsa da anlamlı kaldığı sonucuna ulaşılmıştır. Özcan ve Arı (2014), 19902011 yılları 15 OECD ülkesi için Ar-Ge harcamaları ve ekonomik büyüme arasındaki ilişkiyi panel veri analizini kullanarak ele almışlardır. Yatay kesit bağımlılığını ölçmek için, Breusch ve Pagan (1980)'a ait CDLM testi, birim kök tespit etmek için Smith vd. (2004) tarafından geliştirilen 5 adet bootstrap panel birim kök testi, eş-bütünleşme ilişkisini incelemek için Westerlund ve Edgerton (2007) tarafindan geliştirilen panel bootstrap eş-bütünleşme testi, parametre homojenite testi ve uzun dönem ilişkinin tahmini için Pedroni (2000)'nin heterojen FMOLS yöntemlerini kullanmışlardır. Sonuç, Ar-Ge harcamaları ekonomik büyümeyi olumlu yönde etkilediğini göstermektedir. Pece, Simona ve Salisteanu (2015), Orta ve Doğu Avrupa ekonomileri için, Polonya, Çek Cumhuriyeti ve Macaristan olmak üzere 2000-2013 yılları ekonomik büyüme ve yenilik verileri kullanılarak çoklu regresyon modeli ile analiz edilmiştir. Elde edilen bulgular, ekonomik büyüme ve yenilikler arasında olumlu bir ilişki olduğu yönündedir. Ayrıca, doğrudan yabancı yatırımların, bilgi transferi ve teknolojik süreçlerin geliştirilmesi yoluyla ekonomik büyüme üzerinde önemli bir etkiye sahip olacağını göstermektedir. Eğitim ve beşeri sermayenin de büyüme üzerinde güçlü bir etkisinin olduğu tespit edilmiştir. Inekwe (2015), 2000-2009 y1llarını kapsayan dönemde orta-gelirli ekonomiler ve düşük-orta gelirli ekonomiler olarak gruplandırma yaparak 66 ülke için ekonomik büyüme üzerinde Ar-Ge harcamalarının rolünü incelemiştir. Ar-Ge harcamalarının bu ekonomiler üzerindeki etkisini, dinamik sistem GMM, birleştirilmiş ortalamalı grup ve üç aşamalı en küçük kareler GMM modelleri kullanarak analiz etmiștir. Sonuç, Ar-Ge harcamalarının üst-orta gelirli ülkelerde ekonomik büyüme üzerinde olumlu etkisi olduğunu ancak düşük-orta gelirli ülkelerde Ar-Ge harcamalarının büyümeyi artırma konusundaki etkisinin anlamsız olduğunu göstermektedir. Feki ve Mnif (2016), 2004-2011 yılları 35 gelişmekte olan ülke için girişimcilik, teknolojik yenilik ve ekonomik büyüme arasındaki ilişkiyi statik ve dinamik panel veri tekniğiyle ile test etmişlerdir. Bulgular, girișimciliğin ölçütü olan yeni işletmeler yoğunluğu büyüme için pozitif korelasyon olduğu yönündedir. Ayrıca teknolojik yeniliklerin kısa dönemli büyüme üzerindeki etkisi negatif, uzun dönemli büyüme etkisi ise pozitif olduğu tespit edilmiştir. Freimane ve Balina (2016), 2000-2013 yıllarını kapsayan dönemde Avrupa Birliği'ne üye ülkeler için Ar-Ge harcamaları ve ekonomik büyüme arasındaki ilişkiyi panel veri regresyon analizi kullanarak incelemişlerdir. Elde edilen bulgulara göre, Ar-Ge harcamalarının $\mathrm{AB}$ ülkelerindeki ekonomik büyüme etkisi istatiksel olarak anlamlı bulunmuştur. Ar-Ge katsayısının önemi farklı alt dönemlere göre güçlüdür. Fakat yeni $\mathrm{AB}$ ülkelerinin bir alt örneği ele alındığında anlamlılık düzeyinin düştüğü tespit edilmiştir.

Bu çalışmanın amacı gelişmekte olan ülkeler için Ar-Ge ve büyüme üzerine etkilerini araştırmaktır. $\mathrm{Bu}$ etkilerin araştırılması ile elde edilecek sonuçlar önem arz etmektedir. Çalışmamız dört başlık altında sınıflandırılmıştır. İlk olarak Ar-Ge ve yeniliğin yayılma etki ele alınacak, sonrasında ArGe ve yeniliğin büyüme ile ilişkisi Ar-Ge ve yenilik tabanlı büyüme modelleri ile açıklanacaktır. Çalışmanın son bölümünde ise yapılacak ekonometrik analizde Ar-Ge'nin büyüme üzerindeki etkisi panel veri modeliyle açıklanmaya çalışılacaktır.

\section{Ar-Ge ve Yeniliğin Yayılma Etkisi}

Ar-Ge yayılımının önemi, gelişmekte olan ülkelerin teknolojik açıdan niçin gelişmiş ülkeleri yakalayamadığını açıklamada önemli rol oynamaktadır. Ar-Ge'nin yayılması (R\&D spillover), bir ülkenin, endüstrinin ya da yabancı ortakların "süreç odaklı" yeniliklerden ya da "ürün odaklı" yeniliklerden elde ettiği yarar şeklinde açıklanmaktadır. Süreç odaklı yenilik çeşidi belirli bir ürünün üretim maliyetlerini düşürürken, ürün odaklı yenilik hali hazırdaki ürünlerin yeni ürün ya da daha kaliteli türlerini üretmeyi hedeflemektedir. Griliches (1979), Ar-Ge yayılımını rant yayılımı (rent spillover) ve bilgi yayılımı (knowledge spillover) olarak ikiye ayırmıștır. Rant yayılımı, bilgiye dayalı girdilerin kalite iyileştirmesini tam olarak yansıtmayan bir fiyattan satın alınmasıyla meydana gelir. $\mathrm{Bu}$ sebeple daha çok fiyat belirleme ile ilgili olup, sermaye donanımı ya da malzemeyi kapsamamaktadır. Esas yayılım için önemli olan, bilgi yayılımıdır. Bu durum, bir endüstri ya da bir ülkenin diğer endüstri ya da ülkenin araştırma sonuçlarından faydalanmasıyla gerçekleşir. Mutlak olarak üretken girdilerin satın alınmasını gerektirmemektedir. Bilgi yayılımı da ikiye ayrılmaktadır. Birincisi, tam bir şekilde korunmuş ve kodlanmış bilginin elde edilmesi sonucunda, diğer yenilikçilerin taklit etmesiyle "taklit geliştirme"dir. İkincisi, bilgi stokunun yeni bilgi ve fikirlerin üretilmesinde, önemli bir girdi olarak kabul gördüğü "fikir yaratma"ya dayanmaktadır (Seck, 2012: 439).

Yayılma, yeniliklerin, dünyada herhangi bir yerde ilk kez gerçekleştirilmesinden, diğer ülke ve bölgelere, diğer 
piyasalar ve endüstrilere, piyasaya veya piyasa dışı kanallarla dağılmasıdır. Yayılma sürecini sıklıkla benimseyen firmaların yeni bilgi ve teknolojilerden ders çıkarmaları ve bunları temel almalarından ötürü, yalnızca bilgi ve teknolojinin benimsenmesi değildir. Yayılma süreci yoluyla, yenilikler değişebilir ve orijinal yenilikçiye geri bildirim sağlanabilir (OECD ve Eurostat, 2005).

Literatürde yayılma kavramı "taklit" ve "fırsatçılık" gibi kavramlar olarak da karşımıza çıkmaktadır. Ekonomik büyümenin yapısal sorunlarını dikkate alan birçok ekonomik büyüme teorisinin merkezinde yer alan yeniliklerin yayılması aynı zamanda uzun dönemde sanayilerin ortaya çıkışı, yükseliş ve düşüşleri $\mathrm{S}$ şeklindeki eğriye benzediği ileri sürülmüştür. Freeman vd. (1982) bu iki teoriyi birbiriyle ilişkilendirmeye yönelik çalışmalar yapmışlardır. Yayılma döneminde ortaya çıkan ikincil yenilikleri de içerecek bir şekilde bir "yenilik demeti" kavramı olarak açıklamaya çalışarak bu kavramı yeni sanayilerin hızlı bir biçimde büyümesiyle ilişkilendirmişlerdir. $\mathrm{Bu}$ demetler tüm sektörlerde ekonomik büyüme başlangıcının ana unsuru olarak açıklanabilir. Bu bağlamda yayılma (diffusion) kavramı, belirli bir zaman aralığında yayılmanın ilk aşaması olarak ekonomiyi daha yüksek bir performans seviyesine çıkaran ve birbiriyle ilişkili olarak bir dizi yenilik demetinden oluşan yayılma dalgaları "zarfı" şeklinde ifade edilebilir (Freeman ve Soete, 2004: 404).

Yenilik çalışmalarında yayılma kavramı bir toplum ya da ekonomideki bireylerin ve işletmelerin yeni bir teknolojiyi benimsemeleri ya da eski bir teknolojiyi yeni bir teknolojiyle değiştirme süreci olarak tanımlanmaktadır. Yayılma sadece yeniliklerin belli bir kitleye yayılmasının yararından ziyade, öğrenme, taklit ve yeni teknolojinin yayılması esnasında ortaya çıkan geri bildirim etkilerini, yenilik sürecinin bir parçasını oluşturarak yeniliğin güçlenmesine yardımcı olan bir anlam taşımaktadır. Yayılma sürecinin anlaşılması, işletmeler ve devlet kurumları tarafından bilinçli bir şekilde yürütülen araştırma ve geliştirmenin finansmanı, teknoloji transferi, yeni ürün ve süreçlerin yaratılması gibi faaliyetlerden oluşur. $\mathrm{Bu}$ faaliyetlerin hedefi ekonomik ve sosyal refah düzeyinde iyileştirme sağlamasının sonucunda ne kadar önemli olduğunu anlatan bir anahtar bir durum olarak ifade edilir. Gelişmekte olan ekonomiler, geri kalmış bölge ve teknolojik açıdan gecikmiş işletmeler gelişmiş olanları yakalamaya çalışarak bu yayılım sürecinin önemli bir parçası olabilir (Hall, 2004: 2-3).

Yeniliklerin yayılması, tarihsel, sosyolojik, ekonomik (iş ve pazarlama stratejisi) ve ă̆ teorisi olmak üzere çeşitli perspektiflerden incelenmiştir. Yaklaşım seçimi genellikle ortaya çıkacak sonuçların faydalarına göre belirlenecek ve bir perspektiften gelen bilgilerle başka alanlardaki araştırmaları bilgilendireceğinden şüphe duyulmamaktadır. Bunun önemli bir örneği, belli başlı icatların gelişimi ve yayılmasını tarihsel olarak inceleyen ekonomistler verimlilik değişiminin dinamiklerini belirlerken yayılma süreci rolünü nasıl etkilediği gösterilebilir (Hall, 2004: 4). Yayılma analizi birçok çalışmayla incelenmiş ve bu konuda en çok kabul gören görüş ise Rogers tarafından Yeniliklerin Yayılımı (Diffusion of Innovations) adlı kitabı dikkat çekmiştir.

Rogers yayılma kavramını, bir yeniliğin belli bir kanal vasıtasıyla zaman içinde bir sosyal sistemin üyeleri arasında iletildiği süreç olarak tanımlamaktadır. Mesajların yeni fikirlerle ilgili olduğu özel bir iletişim biçimi olarak, iletişim kavramı da katılımcılar tarafından karşılıklı bilgi alışverişinde bulunduğu bir süreç olarak ifade edilir. Bu bakımdan yayılım 1- bir yeniliğin, 2- belirli bir kanaldan, 3zamanla, 4- bir sosyal sistemin üyeleri arasında iletildiği süreç olarak açıklanmaktadır. Burada yeniliğin yayılmasında dört ana etmen önemli rol oynamaktadır (Rogers, 1983: 5$10)$.

\subsection{Yenilik}

Yenilik, birey ya da bir birim tarafindan yeni olarak benimsenen fikrin uygulanması ya da projesi olarak açıklanır. Birey için fikrin yeni olarak algılanması yeniliğe verilen tepki olarak gösterilirken, fikir bireye yeni görünüyorsa bu bir yeniliktir. Benimsenen yeniliğin "yeni" olma özelliğinin üç yönü vardır. Bunlar "bilgi edinme", "karar verme" ve "ikna etme" olarak ifade edilmektedir. (Rogers, 1983: 11).

Tüm yeniliklerin benimsenmesi ve yayılması beğenildiği anlamı taşımaz. Buna yönelik bazı yeniliklerin zararlı ve ekonomik olmadığını varsayan çalışmalar da yapılmıştır. Bu tarz yenilikler bireysel ya da sosyal sistem tarafindan istenmeyen yenilikler olarak gösterilmektedir. Örneğin, Kaliforniya'daki mekanik domates toplayıcılar tarafından yapılan toplama işlemi büyük ticari çiftçiler tarafından hızlı bir şekilde kabul görmüştür. Ancak küçük ölçekli domates yetiştiricilerine çok pahalı gelmesi sebebiyle binlerce kişinin üretimden çekilmesine sebep olmuştur (Rogers, 1983: 12).

\section{2. İletişim Kanalları}

Yeniliklerin yayılım sürecinin ikinci aşaması olarak iletişim kanalları gösterilmektedir. İletişim, katılımcıların karşılıklı anlayışa varmak için birbirleriyle bilgi paylaştıkları süreç olarak tanımlanır. Yayılım değiştirilebilen enformasyonların yeni fikirlerden kaynaklandığını ileri süren bir iletişim türüdür. Bir yenilik, yeniliği bilen ya da tecrübe sahibi olan bir birey ya da benimseme birimi, yenilik hakkında henüz bilgi sahibi olmayan birey ya da birimler, iki birimi birbirine bağlayan iletişim kanalı bu süreci anlatmada önemli özellikleri oluşturmaktadır. Bir iletişim kanalı mesajların kişiden kişiye iletme aracıdır. Kitlesel medya kanalları, yenilik hakkında bir kitleye farkındalık yaratarak ve bilgilendirerek potansiyel bir benimseyen yapan en hızlı araç olarak bilinmektedir. Kitle iletişim kanalları araçları, radyo, televizyon, gazeteler vb. gibi kaynağının bir ya da birden fazla kişi tarafından oluşturulan bir kitleye erişmesinde destek olan araçlardır. İletişim kanalları, kitlelerin dikkatini çekme ve ikna etmede önemli rol oynayarak, benimseme ve yayılma sağlamaya yardımcı olmaktadır (Rogers, 1983: 1718).

\subsection{Zaman}

Yayılma araştırmalarında zaman boyutunun da bir değişken olarak dâhil edilmesi onun gücünü vurgulamaktadır. Genellikle araştırmalarda zaman boyutu dikkate alınmamıştır. Rogers zaman boyutunu şu şekilde siralamaktadir:

Yenilik karar süreci: Bireyin yenilik ile ilk karşılaştığında benimsemesi ya da reddetmesiyle geçen yenilik zaman sürecidir. 
Yenilik ve benimsemenin sınıflandırılması: Bir kișinin ya da benimseme birimin sistemin diğer üyeleri ile karşılaştırıldığında yeniliği erken ya da geç dönem olarak benimsemelerini gösteren aşamadır.

Benimseme oranı: Bir sistemde kabullenme oranı genellikle bir zaman aralığında yeniliği benimseyen sistem üyelerinin sayısı olarak ölçülen aşamadır (Rogers, 1983: 20).

\subsection{Sosyal Sistem}

Yayılma sürecinin son aşaması sosyal sistemdir. Bir sosyal sistem ortak bir hedefi gerçekleştirmek için problemleri müşterek bir şekilde çözmek için uğraşan birbiriyle ilişkili birimler kümesi şeklinde tanımlanmaktadır. Bir sosyal sistemin üyeleri veya birimleri, gruplar, kuruluşlar ya da alt bir sistem olabilir. Örneğin yayılma çalışmalarında yapılacak bir analizde Asya'nın bir köyündeki köylüler de olabilir ya da bir hastanedeki doktorlar da olabilir. Bütün bu üyeler ortak bir soruna çözüm bulmak için birbiriyle işbirliği yaparlar. Yayılma bir sosyal sistem içinde meydana gelerek yeniliklerin yayılmalarını türlü biçimlerle etkilemektedir. Bu sosyal yapıların, normların yayılma üzerindeki etkisi, yenilik karar türleri ve sonuçları, kanaat önderleri gibi birçok etken yayılma için etkili olmaktadır. Bütün bu konular bir sosyal sistem içinde meydana geldiğinden yayılım süreci içindeki ilişkiyi anlatır (Rogers, 1983: 24).

\section{Ekonomik Büyüme Modellerinde Ar-Ge ve Yenilik}

"Ulusların Zenginliği” kitabında Adam Smith uzmanlaşma ve iş bölümünün verimlilik ve üretim artışı üzerindeki etkilerini ortaya koymuştur. Klasik iktisatçılar teknolojik gelişme ve verimliliğin uzun dönem büyüme performansının temel bileşenlerinden olduğunu ifade etmişlerdir. Teknolojik gelişme ve verimlilik konusunu ele alan diğer bir yazar David Ricardo'dur. Diğer önemli bir yazar olan Karl Marx ise Kapital adlı eserinde bu konuyu detaylı olarak incelemiştir (Taymaz ve Suiçmez, 2005).

Joseph A. Schumpeter ise o zamana kadar üzerinde çok durulmayan "yenilik" kavramına dikkat çekmiş ekonomik büyümenin temel kaynağı olarak yeniliği göstermiştir. Capitalism, Socialism and Democracy adlı eserinde "yaratıcı yıkım" sürecinde yenilik ve gelişmeyle ilgili görüşlerinden bahsederken "kapitalist sistemin durmadan iç dinamiklerden kaynaklanan bir devrim ve yenilenme havası içinde olduğunu ve sürekli eski faktörleri yok edip, yenilerini yarattığını " vurgulamıştır (Schumpeter, 2014: 103). Bu bağlamda Schumpeter yeniliklerin içsel bir olgu olduğuna dikkat çekerek, sürekli yenilikleri ise ekonomik gelişmenin temel nedeni olarak göstermiştir.

Modern büyüme teorilerinin ortaya çıkması 1950'li yıllarda başlamıştır. Tinbergen, emek ve sermaye faktörlerini dikkate alarak oluşturduğu Cobb-Douglas üretim fonksiyonu yardımıyla İngiltere, Fransa, Almanya ve Amerika'daki çıktı büyümesini açıklamaya çalışmıştır. Solow ve Swan tarafindan oluşturulan Neo-klasik büyüme modeli ise temel olarak tam rekabet ve azalan marjinal getiri kavramları üzerine oturtulmuştur. Neo-klasik modelin bazı varsayımlarını eleştiren iktisatçılar 1980'li yıllarda "Yeni Büyüme Teorileri”ni ortaya çıkarmışlardır. Bu büyüme teorileri Lucas, Romer, Barro, Grosmann ve Helpman, Aghion ve Howit tarafından geliştirilen Ar-Ge temelli içsel büyüme modelleri olarak bilinmektedir (Yılmaz ve Akıncı, 2012: 2-3). Şekil 1, içsel büyüme teorileri kapsamında içsel büyümenin belirleyicilerini göstermektedir.

Şekil 1. İçsel Büyümenin Belirleyicileri

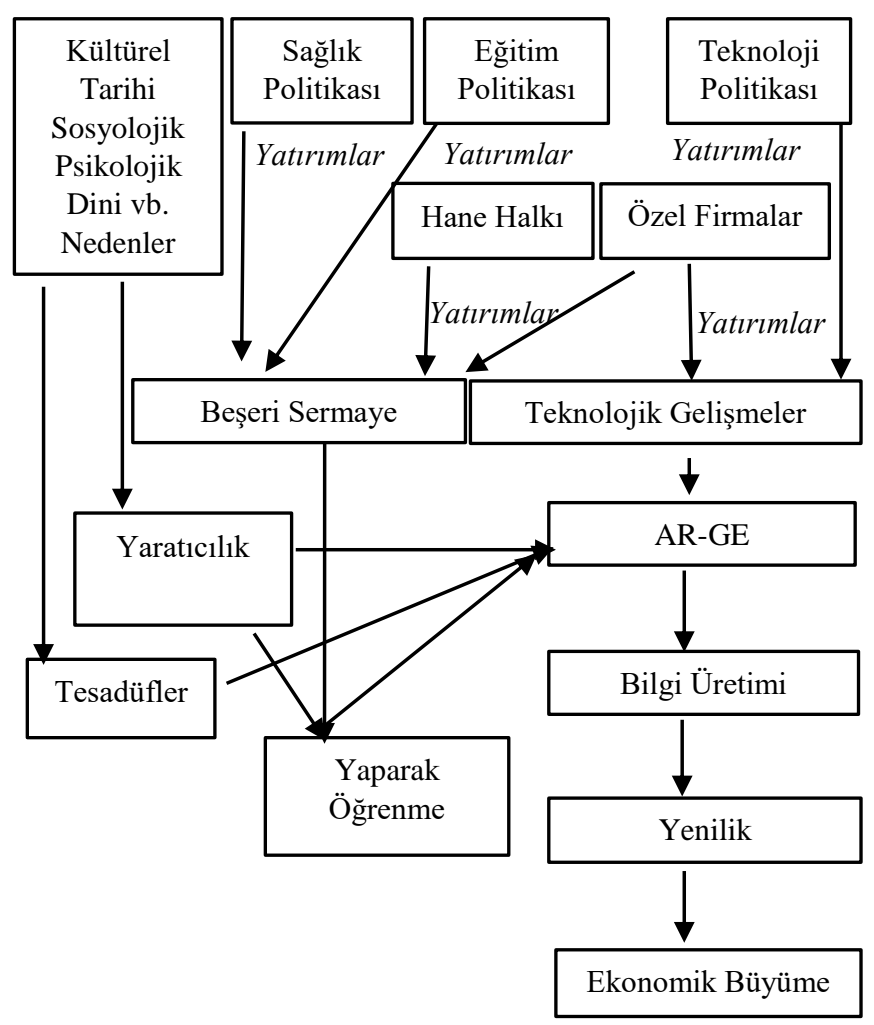

Kaynak: Kibritçioğlu (1998: 217)

Sağlık, eğitim yatırımlarına yapılan harcamalar beşeri sermayeyi ortaya çıkararak Ar-Ge faaliyetlerine neden olmaktadır. Ayrıca ülkelerin kendilerine özgü özellikleri yaratıcılık ve tesadüflerle birlikte Ar-Ge faaliyetlerini meydana getirir. Ar-Ge çalışmaları neticesinde yeni ürünler ortaya çıkmakta, daha etkin üretim yöntemleri geliştirilmekte veya bir ürünün tasarım ve süreçleri geliştirilmesiyle yenilikler ortaya çıkmaktadır. Bu bağlamda ortaya çıkan Schumpeter manada yeniliklerle birlikte ekonomik büyüme gerçekleşmektedir (Taban, 2008: 92).

\subsection{Solow Büyüme Modeli}

Büyüme modellerinde, büyümenin kaynaklarına ilişkin bir takım "yeni” büyüme modellerinin ortaya çıkması büyük ilgi çekmiştir. Yeni tür yaklaşımlar, teknolojik yeniliklerin içsel değişkenler tarafından belirlendiğini vurgulamaktadır. Eski büyüme modelinde "artık" sayılan "teknolojik ilerleme" yeni büyüme modellerinin merkezi haline gelmiştir. Eski Neoklasik büyüme modeli Solow $(1956,1957)$ istikrarlı bir istihdam sağlayan ve basit varsayımlar altında çalışan bir Neo-klasik büyüme teorisinin temellerini atmıştır. $\mathrm{Bu}$ modelde, sermaye stoku ve hasıla, nüfus artışı ve teknolojik ilerleme hızlarının toplamına eşit olacak bir şekilde dengeli bir büyüme oranında artmaktadır. Nüfus artışı ve emeği artıran teknik ilerleme ya da sabit hızda artan teknik ilerleme olmaksızın, tek biriktirilebilen faktör olan sermayenin marjinal getirisinin azalması nedeniyle büyümeyi durduracaktır. Sermaye birikimi, azalan getiriler sebebiyle uzun dönemde yatırımları teşvik edemeyecektir. Sadece iki dışsal etki nüfus artışı ve teknolojik ilerleme büyümeyi 
devam ettirebilir. Bu sebeple büyüme hızı, uzun dönemli dengeli büyüme hızı ekonomik etkilerden bağımsız bir şekilde dişsal olmaktadır (Freeman ve Soete, 2004: 371). Fakat bu büyüme modelinde teknolojik ilerlemenin dışsal olduğu ve azalan getiri varsayımları kabul edildiğinden teknolojik ilerlemenin nasıl sağlanacağı konusu net olarak açıklanamamıştır (Altıntaş ve Mercan, 2015: 351).

\subsection{Arrow "Yaparak Öğrenme"}

Arrow (1962) y1lında "The Economic Implications of Learning by Doing" adlı makalesinde yaparak öğrenme kavramına dikkat çekmiştir. Teknik değişimin incelendiği, zaman içinde olumlu gelişmelere yol açan üretim aktivitesinden kaynaklanan bir hipotez öne sürmektedir. Sermaye-emek ikamesi olasılığı göz ardı edildiğinde kârlar teknik değişikliğin sonucu olarak ortaya çıkar. Serbest girişim sisteminde, yatırım oranı optimumdan daha düşük olmakta, net yatırım ve sermaye stoku bağımlı bir kavram haline gelmekte ve brüt yatırım önde yer alan bir rol oynamaktadır (Arrow, 1962: 156).

Öğrenmenin varlığg bir yatırım eyleminin gelecekteki yatırımcılara fayda sağladığı anlamına gelmektedir. Fakat bu yarar piyasa tarafindan ödenmemektedir. $\mathrm{Bu}$ nedenle rekabetçi model çerçevesinde toplam yatırım tutarının en uygun seviyeden daha aşağı düşmesi beklenmektedir (Arrow, 1962: 168). Burada, öğrenmenin sadece siradan üretimin bir yan ürünü olarak gerçekleştiği varsayılmıştır. Aslında toplum, öğrenmeyi sağlamak amacı ile kurumlar, eğitim ve araştırmalar yaratarak daha hızlı gerçekleşmesini sağlayabilecektir (Arrow, 1962: 172). Arrow, bilginin gelişimini piyasa teşviklerine duyarlı hale getirme girişiminde, sermayedeki artışın bilgiyi "yaparak öğrenme" yoluyla eşit oranda artıracağını varsaymıştır. Fakat bilgiyi kamuya açık bir ürün olarak görmüştür (Romer, 1990: 7677).

\subsection{Romer Büyüme Modeli}

İçsel büyüme modellerinin öncülerinden kabul edilen Romer (1986) "Increasing Returns and Long-Run Growth" adlı çalışması ile dikkat çekmektedir. Romer'e göre, dışa dönük teknolojik değişim göz ardı edildiğinde, uzun vadeli büyümenin esas olarak bilgi birikiminin ileriye dönük, kâr maksimize eden aracılar tarafından yönlendirildiği bir iç enerji teknolojik değişim denge modeli olarak görülebilir. Sermayenin temel biçimi olarak bilgi üzerine odaklanma, standart-toplam toplumsal büyüme modelinin doğal değişikliklerini göstermektedir. Birden fazla geçmişe dönük olarak üretilebilecek fiziki sermayenin aksine, yeni bilgiler, bir araştırma teknolojisinin ürünü olduğu düşünülmektedir. Buna ek olarak, bilgi birikimine yapılan yatırımın, doğal bir dişsallık olduğuna işaret etmektedir. Yeni bir bilginin bir firma tarafından oluşturulması diğer firmaların üretim olanakları üzerinde olumlu bir dışsallık etkisi olduğu varsayıldığı için bilgi patent alınamaz veya gizli tutulamaz. En önemlisi, bilgi stokunun ve diğer girdilerin bir fonksiyonu olarak tüketim mallarının üretimi, artan getiri sergileyen mallardır. Bilgi artan bir marjinal ürüne sahiptir. Sermayenin azalan marjinal verimliliği sergilediği modellerin aksine, bilgi sınırları olmadan büyür. Diğer tüm girdiler sabit tutulsa bile, bilginin sabit olduğu ve yeni araştırmalar yapılmadığı kararlı durumda durdurmanın uygun olmayacağına dikkat çekilmiștir (Romer, 1986: 1003).

Romer (1990) çalışmasında büyüme yaklaşımını Ar-Ge faaliyetleri üzerine kurmuştur. $\mathrm{Bu}$ modelde büyüme, teknolojik değişimden kaynaklanmaktadır. Teknolojinin girdi olarak ayırt edici özelliği, ne bir konvansiyonel malın ne de bir kamu malının olmamasıdır. Teknoloji rakipsiz, kısmen dışarıda bırakılabilir bir maldır. Rakipsiz bir mal olmasından kaynaklanması nedeniyle, fiyat alan rekabet desteklenemez. Bunun yerine, denge tekelci rekabete dayanmaktadır (Romer, 1990: 71).

Romer'e göre araştırma sektörü, yeni bilgi üretmek için beşeri sermayeyi ve mevcut bilgi stokunu kullanmaktadır. Özellikle yeni dayanıklı tüketim malları için tasarımlar üretmektedir. Ara mallar sektörü, son fiyatlarla üretimde kullanılmak üzere herhangi bir zamanda kullanılabilen çok sayıda üretici dayanıklılığının üretilmesi için geçmişten günümüze çıktılar ile birlikte araştırma sektöründeki tasarımları kullanmaktadır. Pratikte, yeni bir tasarım ve yeni malın üretimi için aynı firmada yer alması için araştırma yapılması beklenebilir. Tasarım çalışması ya içeride ya da ayrı bir firmada gerçekleşebilir. Patentini gerçek mal üreten firmaya satar. Çıktı ya tüketilebilir ya da yeni sermaye olarak kaydedilebilmektedir (Romer, 1990: 79).

Şekil 2. Romer' in Büyüme Modeli

Faiz Oranı

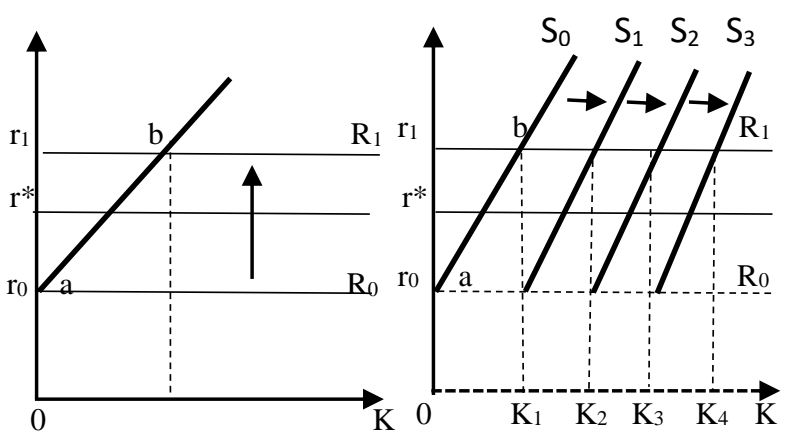

(a) Büyümenin Başlamas1

(b) Bilgi Sermayesinin Büyümesi

Kaynak: Parasız (2008)

Şekil 2'de yatay eksende bilgi sermaye stoku (K), dikey eksende ise reel faiz oranı gösterilmektedir. Bilgi sermaye arzı, yukarıya doğru eğilimli olan $\mathrm{S}_{0}$ eğrisiyle belirtilmiştir. $\mathrm{Bu}$ eğri boyunca, diğer koşulların değişmediği varsayılırsa reel faiz oranı yükseldiğinde bilgi sermaye birikimine ayrılan kaynak ve tasarruf miktarı artacaktır. Bilgi sermayesi zaman tercih oranından daha yüksek bir getiri sağlarsa, talep edilen bilgi sermaye miktarı sınırsız olacaktır. Fakat bilgi sermayesi zaman tercih oranından daha düşük getiri sağlarsa bu durumda bilgi sermaye talebi sıfır olacaktır. Başlangıçta gösterilen bilgi sermayesi getiri oranı $\mathrm{r}_{0}$ 'dır ve Şekil 2'nin (a) bölümünde $\mathrm{R}_{0}$ doğrusuyla gösterilmiştir. Bu getiri oranında denge reel faiz oran $1 \mathrm{r}_{0}$ 'dır ve bilgi sermayesi yoktur, ekonomi a noktasındadır. Bilimsel metotlarda ve $\mathrm{Ar}-\mathrm{Ge}$ faaliyetlerindeki gelişmeler bilgi sermayesinin oranını yükselterek getiri oranı doğrusu $\mathrm{R}_{1}$ 'e kaydırır. Bunun sonucunda bilgi sermayesi $\mathrm{K}_{1}$ 'e yükselir ve ekonominin $b$ noktasına hareket etmesini sağlar. Ekonomi bu şekilde bir büyüme dönemi geçirmiş olacak ve bilgi sermaye stoku 
artığı için GSMH'de artış yaşanacaktır. Ekonomik büyüme kesintiye uğramadan sonsuza dek sürebilecektir. Şekil 2'nin (b) bölümünde ise, büyüme süreci anlatılmaktadır. Zaman tercih oranı $\mathrm{r}^{*}$ olarak gösterilir. Tasarruf pozitif olduğu için arz eğrisi sağa kayacak ve tasarruf eğrisinin sağa kayma hızı ise reel faiz oranının zaman tercih oranı aşmasına bağlı olarak gerçekleşecektir. Bu bağlamda ekonomik büyüme hızı daha fazla olacaktır. Ekonomik büyüme oranı insanların icat yeteneklerine, yeniliğin getiri oranı ve tasarruf oranını etkileyen zaman tercihine bağlı olarak gerçekleşecektir (Parasız, 2008: 193-194-195).

\subsection{Lucas Büyüme Modeli}

Lucas'ın (1988) makalesinde beşeri sermaye kavramına dikkat çekerek ekonomik büyüme ile ilişkisini ele almıştır. Lucas çalışmasında teknolojik gelişme, beşeri sermeye ve fiziksel sermaye üzerinde odaklanmıştır. Beşeri sermayenin modele dâhil olmasıyla teknolojinin ekonomik büyüme sürecini şu şekilde açıklamaktadır. Daha önce iki işçinin yaptığı bir işi teknolojiyi kullanan bir işçinin yapması verimlilik artışına sebep olarak ekonomik büyümeye katkı sağlayacağını ileri sürmüştür (Lucas, 1988: 17). Lucas'a göre teknolojik yenilikler, sermaye malları ve beşeri sermaye ile ekonomik büyüme arasında doğrudan bir ilişki vardır. Bu bağlamda teknolojik yenilikler içeren ürünlerin ve uzun dönem büyümenin kaynağı beşeri sermaye olarak adlandırılan çalışanın bilgi-beceri ve deneyimleri olarak açıklanmaktadır (Gürak, 2006: 118).

\subsection{Barro Büyüme Modeli}

Robert J. Barro (1990) "Goverment Spending in a Simple Model of Endogenous Growth" isimli çalışmasında ele aldığ büyüme modeline kamu harcamalarını dâhil etmiştir. Verimli alanlara kamunun yapacağı yatırım ve harcamaların ekonomik büyümeye pozitif bir etki yaratacağını vurgulamaktadır (Erdoğan ve Canbay, 2016: 37).

Ar-Ge faaliyetlerinin faydalarını önemle vurgulayan Robert J. Barro, kamusal gelirler politikasının (vergi politikasının) bu çeşit faaliyetlerin mobilitesini etkilediğini belirtmiştir. Barro’ya göre Ar-Ge faaliyetleri, ağır yük gerektirmeyen kamusal gelirler politikasının uygulandığı ülkelerde tercih edilir. Bu nedenle, bu tür çalışmaları caydıracak vergi politikalarından kaçınılması gerektiği ileri sürmüştür (Orhan ve Erdoğan, 2016: 582).

\subsection{Aghion ve Howitt Büyüme Modeli}

Aghion ve Howitt (1992) tarafindan geliştirilen modelde ürün kalitesini artıran endüstriyel yeniliklerde dikkat edilmeyen bir nokta üzerinde durmaktadır. Bu nokta içsel büyüme teorisinde eskime faktörü olarak adlandırılır. Yeni girdiler kendinden öncekinin yerini alır ve bununla birlikte tekeli de sona erdirmiş olur. Bu süreç "yaratıcı tahribat" olarak açıklanmaktadır. Aghion ve Howitt'in büyüme modeli aynı zamanda dikey yeniliklerin üretildiği yaklaşımla dikkat çeker. Büyümenin kaynağını rekabetçi bir araştırma (Ar-Ge) sektörü tarafindan gerçekleştirilen dikey yenilikler oluşturmaktadır. (Aghion ve Howitt, 1992: 323-324). Modelin özellikleri şu şekilde sıralanabilir:

(i) Yenilikler büyümenin kaynağıdır.

(ii) Yenilikler "içseldir". (iii) Yeniliklerin sebebi rekabetçi firmaların araştırmalarıdır.

(iv) Her yenilik "yeni" bir malın üretimine sebep olur. Bu yeniliğin tüketim malı daha etkin üretilir.

(v) Ar-Ge sektöründe istihdam sabittir.

(vi) Araştırma neticesinde elde edilen yenilik için patent alınır. Böylece firmalar tekelci kâr elde etmiş olur. Firmaları yenilik ve araştırmaya teşvik eden bu tekelci kârlar olarak gösterilir. Fakat bir sonraki dönemde bulunan yenilik sebebiyle eski ürünlerin modası geçer. Bu bağlamda eski ürünler için tekelci kârlar sona erecek ve yeni dönemin kârları başlayacaktır.

(vii) Büyüme oranı; yeniliklerin miktarı, Ar-Ge'nin verimliliği ve nitelikli işgücünün miktarı ile ilişkilidir (Taban, 2008: 104).

\subsection{Grossman ve Helpman Büyüme Modeli}

Ekonomilerin özellikleri uzun dönemli büyüme performanslarının karşılaştırılması bakımından önem arz etmektedir. Karşılaştırmalı üstünlükler teorisi bir ülkenin bilgi yaratmada sermaye ya da teknoloji yoğun malların üretiminde ne oranda uzmanlaşacağının önemli bir göstergesidir. Ayrıca nispeten büyük ölçekli ekonomiler büyük olmanın avantajı ile daha fazla firsat yaratarak teknoloji teşviklerini artırdığı bilinmektedir. Bunun yanı sıra ucuz ve hızlı haberleşmeyle birlikte bilgi ve fikirler hızlı bir biçimde sınırları aşarak yayılma sağlamaktadır. Uluslararası sermaye piyasalarında etkin olmak, bilgi sermayesini de kapsayacak şekilde bütün sermayelerde yapılacak yatırımları finanse etmede geniş bir biçimde firsatlar sunmaktadır (Grossman ve Helpman, 1990: 86).

Grossman ve Helpman (1990) çalışmasında içsel yenilik ve beşeri sermaye oluşumunu tasarladığı modelleme yaklaşımda, dış ticaret politikası ile uzun dönem büyüme performansındaki ilişkiyi açıklamaktadır. Grossman ve Helpman'a göre AR-GE'yi üstlenmede karşılaştırmalı üstünlüğe sahip bir ülke tarafindan araştırmalar desteklenecek olursa büyüme oranının artacağını, fakat benzer bir destekleme yenilikçilik yerine imalata kayarsa büyüme oranının düşebileceğini ifade etmişlerdir. Korumacı politikaların aktif olduğu bir ülkede ise kaynaklar Ar-Ge'den üretim alanına kayarken korumacı politikaların etkin olmadığı bir ülkede kaynaklarda tersi bir durum ortaya çıkmaktadır. Bu bağlamda serbest diş ticaret stratejilerini benimseyen ülkelerin, korumacı politikaları benimseyen ülkelere kıyasla daha hızlı büyüme performansı sergileneceği ileri sürülmüştür (Grossman ve Helpman, 1990: 90-91).

\section{Ekonometrik Analiz}

Çalışmamızda Ar-Ge harcamalarının büyüme üzerindeki etkisi 1998-2013 dönemi için 15 gelişmekte olan ülke verisi ele alınarak analiz edilmiştir. Analizde ele alınan ülkeler Arjantin, Azerbaycan, Belarus, Çin, Kazakistan, Kolombiya, Kosta Rika, Meksika, Makedonya, Panama, Romanya, Rusya, Sırbistan, Türkiye, Ukrayna'dır. Veriler World Bank web sitesinden yıllık olarak elde edilmiştir. Ele alınan ülke grubunun seçiminde ülkelerin hâsıla ve Ar-Ge harcama seviyeleri belirleyici olmuştur. $\mathrm{Bu}$ gelişmekte olan ekonomiler, nispeten yüksek büyüme performanslarına sahip 
orta yüksek gelir grubunda yer alan ülkelerdir. Denklem 1 seriler arasındaki ilişkilerin tahmininde kullanılmıştır.

$$
\text { Büyüme }_{i t}=\beta_{0}+\beta_{1} \mathrm{ARGE}_{i t}+\beta_{2} \dot{I}_{\mathrm{HR}} \mathrm{R}_{i t}+\beta_{3} \mathrm{DYY}_{i t}+\varepsilon_{i t}
$$

Denklem (1)'de ARGE: Ar-Ge harcamaları serisini, Büyüme: gayrisafi yurtiçi hâsıla büyüme oranını, İHR: ihracat hacminin hasılaya oranı ve DYY: doğrudan yabanc1 yatırımların hasılaya oranını temsil etmektedir. Ar-Ge harcamalarının büyüme üzerindeki etkilerinin incelenmesi için ele aldığımız veriler birden çok ülke ve zaman içerdiğinden panel veri ekonometrisi ile tahmin edilmiştir.

Panel veriler, çeşitli birimlerin, örn; bireylerin, ülkelerin, firmaların, hane halklarının yatay kesitini belirli bir gözlem periyodu boyunca bir araya getirilmesi olarak ifade edilmektedir (Arun ve Yildırım, 2017).

Çalışmada öncelikle ele alınan serilerin birim kök durumu incelenecektir. Birim kök durumunun araştırılmasında literatürde yoğunlukla kullanılan Levin, Lin \& Chu (LLC), Im, Pesaran ve Shin (IPS), ADF ve PP testlerinden yararlanılmıştır. Tablo 1'de ilgili serilerin durağanlık durumu görülmektedir.

Tablo 1. Birim Kök Analiz Sonuçları

\begin{tabular}{|c|c|c|c|c|}
\hline & Sabitli & Olasılık & Sabitli ve Trendli & Olasilık \\
\hline \multicolumn{5}{|c|}{ İHR } \\
\hline LLC & -1.210 & 0.113 & -2.926 & 0.001 \\
\hline IPS & -1.771 & 0.038 & -2.917 & 0.001 \\
\hline $\mathrm{ADF}$ & 47.74 & 0.021 & 59.24 & 0.001 \\
\hline PP & 36.98 & 0.177 & 68.69 & 0.000 \\
\hline \multicolumn{5}{|c|}{ DYY } \\
\hline LLC & -6.722 & 0.000 & -4.861 & 0.000 \\
\hline IPS & -6.301 & 0.000 & -2.746 & 0.003 \\
\hline $\mathrm{ADF}$ & 90.07 & 0.000 & 50.00 & 0.012 \\
\hline $\mathrm{PP}$ & 71.96 & 0.000 & 56.22 & 0.002 \\
\hline \multicolumn{5}{|c|}{ Büyüme } \\
\hline LLC & -8.012 & 0.000 & -8.335 & 0.000 \\
\hline IPS & -6.021 & 0.000 & -4.084 & 0.000 \\
\hline $\mathrm{ADF}$ & 88.41 & 0.000 & 64.51 & 0.000 \\
\hline $\mathrm{PP}$ & 79.62 & 0.000 & 51.46 & 0.008 \\
\hline \multicolumn{5}{|c|}{ ARGE } \\
\hline LLC & 0.143 & 0.557 & -2.172 & 0.014 \\
\hline IPS & 0.703 & 0.759 & -0.458 & 0.323 \\
\hline $\mathrm{ADF}$ & 31.34 & 0.398 & 36.43 & 0.194 \\
\hline PP & 24.43 & 0.751 & 36.22 & 0.200 \\
\hline
\end{tabular}

Tablo 1'deki sonuçlar incelendiğinde İHR, DYY, Büyüme serilerinin düzeyde durağan oldukları ancak ARGE serisinin durağan olmadığı sonucuna ulaşılmıştır. ARGE serisinin birinci farkı alındığında serinin durağanlaştığı görülmüştür. Serilerin durağanlık durumlarının incelenmesinin ardından Ar-Ge harcamalarının büyüme üzerindeki etkilerinin analiz edilmesine geçilebilir. Tahmin için panel EKK metodolojisi kullanılmıştır. Ancak panel EKK testi için sabit etkiler ya da rassal etkiler modelleri tahmin edilebilmektedir. Çalışmamızda sabit ya da rassal etkiler modellerinden hangi tahmincisinin etkin olduğunun analiz edilmesi için Hausman testi kullanılmıştır. Tablo 2'de Hausman test sonuçları gösterilmektedir.

Tablo 2. Hausman Test Sonuçları

\begin{tabular}{lccc}
\hline Test Summary & Chi-Sq. Statistic & Chi-Sq. d.f. & Prob. \\
\hline Cross-section random & 0.000000 & 3 & 1.0000 \\
\hline
\end{tabular}

Tablo 2'deki Hausman test sonuçlarına bakıldığında rassal etkiler modelinin tahmincisinin etkin olduğunu öne süren temel hipotez kabul edilmektedir. Rassal etkiler modeli için panel EKK analiz sonuçları Tablo 3'de görülmektedir.

Tablo 3. Panel EKK Analiz Sonuçları

\begin{tabular}{|c|c|c|c|c|}
\hline \multicolumn{5}{|c|}{ Bağımlı Değişken: Büyüme } \\
\hline Değişkenler & Katsayılar & Std. Hata & t-İst. & Olasılık \\
\hline$\overline{\mathrm{C}}$ & 0.937554 & 1.286138 & 0.728969 & 0.4668 \\
\hline İHR & 0.076048 & 0.031608 & 2.405947 & 0.0169 \\
\hline DYY & 0.248222 & 0.059916 & 4.142864 & 0.0000 \\
\hline $\mathrm{D}(\mathrm{ARGE})$ & -1.695554 & 4.672941 & -0.362845 & 0.7171 \\
\hline
\end{tabular}

Tablo 3'deki sonuçlar incelendiğinde doğrudan yabancı yatırımlar ve ihracat serileri büyüme oranını istatistiksel olarak anlamlı şekilde ve teorik beklentimize uyumlu şekilde etkilemektedir. Ancak çalışmamızın odak noktasını oluşturan Ar-Ge harcamalarının büyüme üzerinde istatistiksel olarak anlamlı bir etkisinin mevcut olmadığı görülmektedir.

\section{Sonuç}

Ülkelerin ekonomik ve sosyal refah seviyelerindeki artışın en önemli göstergelerinden biri olan ekonomik büyüme olgusu, gelişmiş ve gelişmekte olan ülkelerin en çok üzerinde durduğu kavramların başında gelmektedir. Günümüzde uzun dönemli büyümenin kaynağı olarak teknolojik gelişmeler gösterilmektedir. Teknolojik gelişmelerin büyüme üzerindeki etkisi uzun zamandan beri birçok iktisatçı tarafindan incelenen konu olmuştur. Teknolojik gelişmeleri dişsal kabul eden Neo-klasik iktisatçılar arasında Solow gelmektedir. Solow, büyüme artışının yalnız emek ve sermaye artışından kaynaklanmadığını ileri sürmüş bununla birlikte teknolojik gelişmeye dikkat çekmiştir. Fakat modelde teknolojinin dışsal bir değişken olması ve azalan verimler yasası geçerli olduğu için teknolojik gelişmenin nasıl sağlanacağı açıklanamamıştır. Schumpeter öncülüğünde geliştirilen içsel büyüme teorileri ise teknolojik gelişmelerin büyüme üzerinde önemli bir etkiye sahip olduğunu ileri sürerek ArGe ve yeniliği azalan verimler yasasının ortaya çıkışını engellemede önemli faktör olarak göstermiştir.

Uluslararası rekabet alanındaki teknolojinin rolü önemli bir belirleyici olmuş ve ekonomik gelişmişliği gösteren siniflandırmalar teknoloji üreten ve üretmeyen ülkeler şekline dönüşmüştür. Bundan dolayı ülkeler ve firmalar, teknolojik değişime ve ekonomik şartlara uyum stratejileri belirleyerek uygulamak zorunda kalmışlardır (Öztürk, 2003: 212).

Teknolojik gelişmelerin nedenleri arasında gösterilen "yenilik" (inovasyon) ve "Ar-Ge" kavramları bireylerin, 
firmaların ve ülkelerin üzerinde durduğu kavramlar arasındadır. Yeni ve yaratıcı bir fikrin ortaya çıkması, uygulanması ve bu fikrin ticarileştirilmesi gibi aşamaları içeren yenilik; "Yenilik = İcat + Ticarileştirme" olarak formülize edilmiştir. Ar-Ge ise küreselleşen rekabet ortamında fark yaratmak için, yeni ürün ve üretim yöntemlerinin ortaya çıkması ve yeni pazarlara sunulmasını sağlama gibi büyük önem arz eden sistemli çalışmalar olarak ifade edilebilir.

Bu çalışmada, 1998-2013 dönemi yıllık verileri kullanılarak Ar-Ge harcamalarının ekonomik büyüme üzerindeki etkisi 15 gelişmekte olan ülke için panel veri analizi ile incelenmiştir. Sonuç olarak Ar-Ge harcamalarının büyüme üzerinde istatistiksel olarak anlamlı bir etkiye sahip olmadığı görülmüştür.

Ar-Ge harcamalarının büyüme üzerinde istatistiksel olarak anlamlı bir etkiye sahip olmamasının çeşitli nedenleri olabilir. Seçilen ülke grubu gelişmekte olan ülkeler olduğu için Ar-Ge harcamaları nispeten düşük seviyelerdedir. Ar-Ge harcamalarının verimli olabilmesi ürüne dönüşmesi durumunda olabilir. Diğer bir ifade ile Ar-Ge harcamaları, ürüne dönüşmesi ile büyümeye katkı yapabilir. Yeni ürün geliştirmeye yönelik Ar-Ge'den elde edilecek çıktı nispeten uzun dönemde gerçekleşecektir. $\mathrm{Bu}$ nedenle büyümeye üzerindeki gecikmeli etkiler analize dâhil edilmemiştir. Genel olarak gelişmekte olan ülkelerin yüksek teknolojili ürünler üretimi ve ihracatı sınırlıdır.

Çalışmamızda son olarak Ar-Ge harcamalarının büyümeye katkı yapmasını sağlayabilecek bazı politika önerilerine yer verilmiştir:

(i) Gelişmekte olan ülkelerin gelişmiş ülke seviyelerine ulaşabilmeleri ve sürdürülebilir bir ekonomik büyüme oranını yakalayabilmeleri için katma değeri yüksek olan yüksek teknolojili ürünler üretip ihraç etmeleri önemlidir. Bu ürünler ile ülkeler, kârlılık oranını artırabilir ve sermaye birikimi sağlayabilir.

(ii) Yeniliğin en temel unsurlarından olan eğitim politikasıyla nitelikli işgücünün yetiştirilmesine yönelik düzenlemeler yapılabilir.

(iii) Nitelikli işgücünün artırılmasına yönelik, yaratıcı düşünceyi destekleyen eğitim politikaları geliştirilebilir.

(iv) Nitelikli işgücü olarak gösterilen Ar-Ge personelinin milli gelire oranı artırılabilir ve desteklenebilir.

(v) Beşeri sermaye, yenilik için temel unsurlardan biri olarak gösterilmektedir. $\mathrm{Bu}$ bağlamda, beşeri sermayenin her türlü entelektüel bilgi birikiminin yenilik sürecine dâhil edilmesiyle iyileştirme ve geliştirme sağlanabilir.

(vi) Yeni teknolojilerin gelişmekte olan ülkelere kazandırılmasında önemli yollardan biri olarak gösterilen teknoloji transferleri teknoloji yoğun üretim yapmak isteyen firmalar için önemlidir. $\mathrm{Bu}$ bağlamda teknoloji transferi için en güvenli kanal olarak gösterilen doğrudan yabancı yatırım girişleri artır1labilir.

(vii) Hem özel hem de kamu tarafından yenilik için Ar-Ge desteği sağlanabilir.

(viii) Ar-Ge yatırımlarını teşvik edebilmek amacıyla Ar-Ge harcamalarına vergi kolaylıkları sağlanabilir.

(ix) Ülkeler yenilikçi bakış açısıyla hareket edebilmeleri için, yenilikçi bakış açısını benimseyen başarılı ülke örneklerini inceleyebilir ve bu doğrultuda bilim ve teknoloji çalışmalarına ağırlık verebilir.

\section{Kaynakça}

Aghion, P., \& Howitt, P. (1992). A Model of Growth Through Creative Destruction. The Econometric Society, (60)2, 323-352.

Altın, O., \& Kaya, A. (2009) Türkiye'de Ar-Ge Harcamaları ve Nedensel İlişkinin Analizi. Ege Akademik Bakış, (9)1, 251-259.

Altıntaş, H., \& Mercan, M. (2015). Ar-Ge Harcamaları ve Ekonomik Büyüme İlişkisi: OECD Ülkeleri Üzerine Yatay Kesit Bağımlılığı Altında Panel Eş-bütünleşme Analizi. Ankara Üniversitesi SBF Dergisi, (70)2, 345376.

Arrow, K. J. (1962). The Economic Implications of Learning by Doing. The Review of Economic Studies, 29(3), 155173.

Arun, K., \& Yıldırım, D. Ç. (2017). Effects of Foreign Direct Investment on Intellectual Property, Patents And R\&D. Queen Mary Journal of Intellectual Property, 7(2), 226241.

Barutçugil, İ. (2009). ARGE Yönetimi. 1. Baskı, Kariyer Yayınları, İstanbul.

Erdoğan, S., \& Canbay, Ş. (2016). İktisadi Büyüme ve Araştırma \& Geliştirme (Ar-Ge) Harcamaları İlişkisi Üzerine Teorik Bir İnceleme. Muş Alparslan Üniversitesi Sosyal Bilimler Dergisi, (4)2, 29-44.

Falk, M. (2007). "R\&D Spending in the High-Tech Sector and Economic Growth. Research in Economics, (61)3, 140-147.

Feki, C., \& Mnif, S. (2016). Entrepreneurship, Technological Innovation, and Economic Growth: Empirical Analysis of Panel Data. Journal of the Knowledge Economy, (7)4, 984-999.

Freeman, C., \& Soete, L. (2004). Yenilik İktisadl. (çev. Ergun Türkcan). 5. Baskı, Tübitak Yayınları, Ankara.

Freimane, R., \& Bāliṇa, S. (2016). Research and Development Expenditures and Economic Growth in the EU: A Panel Data Analysis. Economics and Business, (29)1, 5-11.

Grossman, G., M., \& Helpman, E. (1990). Trade, Innovation, and Growth. American Economic Association, 80(2), 8691.

Gürak, H.(2006). Ekonomik Büyüme ve Küresel Ekonomi. Ekin Kitabevi, Bursa.

Hall, B., H., (2004). Innovation and Diffusion. NBER Working Paper Series, WP No. w10212. (Erişim: 09.02.2017), http://www.nber.org/papers/w10212.pdf

Inekwe, J., N. (2015). The Contribution of R\&D Expenditure to Economic Growth in Developing Economies. Social Indicators Research, (124)3, 727-745.

Kibritçioğlu, A. (1998). İktisadi Büyümenin Belirleyicileri ve Yeni Büyüme Modellerinde Beşeri Sermayenin Yeri. Ankara Üniversitesi SBF Dergisi, 10(53), 207-230. 
Korkmaz, S. (2010). Türkiye'de Ar-Ge Yatırımları ve Ekonomik Büyüme Arasındaki İlişkinin VAR Modeli ile Analizi. Yaşar Üniversitesi Dergisi, (20)5, 3320-3330.

Lucas, R. E. (1988). On The Mechanics of Economic Development. Journal of Monetary Economics, 22, 3-42.

MÜSİAD, (2012). Küresel Rekabet İçin Ar-Ge ve Inovasyon. MÜSİAD Araştırma Raporları, No. 76. İstanbul: MÜSİAT Yayınları.

OECD \& Eurostat (2005). Oslo Kllavuzu: Yenilik Verilerinin Toplanması Íçin Illkeler. Ankara: Tübitak. (Erişim: 12.10.2017),

http://www.tubitak.gov.tr/tubitak_content_files/BTYPD /kilavuzlar/Oslo_3_TR.pdf

OECD (2002). Frascati Kllavuzu: Araştırma ve Deneysel Geliştirme Taramalarl Için Önerilen Standart Uygulama. Ankara: Tübitak.

Orhan, O., Z., \& Erdoğan, S. (2016). İktisada Giriş. Kocaeli: Umuttepe Yayınları.

Özcan, B., \& Arı, A. (2014). Araştırma-Geliştirme Harcamaları ve Ekonomik Büyüme İlişkisi: Panel Veri Analizi. Maliye Dergisi, (166), 39-55.

Öztürk, S. (2003). Günümüz Dünyasında Üretim Faktörlerinden Teknolojinin Gelişimi ve Önemi. Yönetim ve Ekonomi: Celal Bayar Üniversitesi İtisadi ve İdari Bilimler Fakültesi Dergisi, 10(2), 209-218.

Parasız, İ. (2008). Ekonomik Büyüme Teorileri. 3. Bask1, Ezgi Kitabevi Yayınları, Bursa.

Pece, A. M., Simona, O. E. O., \& Salisteanu, F. (2015). Innovation and Economic Growth: An Empirical Analysis for CEE Countries. Procedia Economics and Finance, (26), 461-467.

Petrariu, I.R, Bumbac, R., \& Ciobanu, R. (2013). Innovation: a path to competitiveness and economic growth. The case of CEE countries. Theoretical and Applied Economics, Vol. XX, No. 5 (582), 15-26.

Rogers, E. M. (1983). Diffusion of Innovations, 3nd ed., The Free Press A Division of Macmillan Publishing Co., Inc. 866 Third Avenue, New York, N. Y. 10022.

Romer, P. M. (1986). Increasing Returns and Long-Run Growth. The Journal of Political Economy, 95(5), 10021037.

Romer, P. M. (1990). Endogenous Technological Change. The Journal of Political Economy, 98(5), 71-102.

Samimi, A. J., \& Alerasoul, S. M. (2009). R\&D and Economic Growth: New Evidence from Some Developing Countries. Australian Journal of Basic and Applied Sciences, (3)4, 3464-3469.

Schumpeter, J. A. (2014). Kapitalizm Sosyalizm ve Demokrasi. (çev. Hasan İlhan). Ankara: Alter Yayınları.

Seck, A. (2012). International Technology Diffusion and Economic Growth: Explaining the Spillover Benefits to Developing Countries. Structural Change and Economic Dynamics, (23)4, 437-451.

Silaghi, M. I. Pop., Alexa, D. J. Cristina, \& Litan, C.,(2014). Do Business and Public Sector Research and
Development Expenditures Contribute to Economic Growth in Central and Eastern European Countries? A Dynamic Panel Estimation. Economic Modelling, (36), 108-119.

Taban, S. (2008). İktisadi Büyüme: Kavram ve Modeller. Ankara: Nobel Yayınlar1.

Taymaz, E., \& Suiçmez, H. (2005). Türkiye' de Verimlilik, Büyüme ve Kriz. Türkiye Ekonomi Kurumu.

Wang, D. H-M. Y., Tiffany H-K., \& Liu, H-Q. (2013). Heterogeneous Effect of High-Tech Industrial R\&D Spending on Economic Growth. Journal of Business Research, (66)10, 1990-1993.

Yaylalı, M., Akan, Y., \& Işık, C. (2010). Türkiye'de Ar-Ge Yatırım Harcamaları Ve Ekonomik Büyüme Arasındaki Eş-Bütünleşme ve Nedensellik İlişkisi: 1990-2009. Bilgi Ekonomisi ve Yönetimi Dergisi, (5)2, 13-26.

Yılmaz, Ö., \& Akınc1, M. (2012). Iktisadi Büyüme ve Makroekonomik Belirleyicileri. Ankara: Nobel Yayınları. 